\title{
Večjezične kratke folklorne oblike: primeri iz Goriških brd
}

ב Marjeta Pisk, Katarina Šrimpf Vendramin =

Prispevek obravnava kratke folklorne oblike, zabeležene v Goriških brdih v 20. in začetku 21. stoletja, ki jih lahko analiziramo z vidika nejezikovnih ali neetično vezanih folklornih značilnosti. Jezik teh folklornih oblik je mešanica narečnih oblik kontaktnih jezikov (slovenščina, italijanščina, delno furlanščina). Na primerih zbranega gradiva analiziramo, v katerih zvrsteh kratkih folklornih oblik se pojavlja večjezičnost, kakšno funkcijo ima in kako se v njih odražajo značilnosti ozemlja. Primerjamo vire ali vzporednice $\mathrm{v}$ objavljenem slovenskem in italijanskem gradivu ter ga analiziramo v okviru raziskav otroške folklore na Slovenskem. Preučevanje dvojezičnih in večjezičnih folklornih oblik iz Goriških brd se osredinja na vprašanje, ali in zakaj je večjezičnost najbolje ohranjena $\mathrm{v}$ kratkih folklornih oblikah in predvsem $\mathrm{v}$ otroški folklori.

KLJUČNE BESEDE: Goriška brda, kratke folklorne oblike, jezikovno stikanje, dvojezičnost, večjezikovne folklorne oblike, mejna območja, otroška folklora
The article focuses on short folklore forms recorded in the Gorica Hills (slv. Goriška brda) in the 20th and early 21 st centuries, which can be considered as non-linguistic or non-ethnically bound folklore features. The language of these folklore forms is a mixture of the dialectal forms of the contact languages (Slovene, Italian, partly Friulian). Using the examples of the collected material, we analyse in which genres of the short folklore forms multilingualism appears, what function it has and how the characteristics of the territory are reflected in them. We compare sources or parallels in published Slovenian and Italian material, and analyse the material in the context of research on literary children's folklore in Slovenia. The study of bilingual and multilingual folklore forms from Goriška brda focuses on the question of whether and why multilingualism is best preserved in short folklore forms and especially in children's folklore.

KEYWORDS: Gorica Hills, short folklore forms, multilinguality, languages in contact, bilingualism, multilingual folklore forms, border areas, children's folklore

\section{UVOD}

Jezik ni le instrument za sporazumevanje, temveč je močno prepleten s kulturo, družbo, naravnimi danostmi itd. (Vygotski 1967; Babič 2019: 21), torej z okoljem, v katerem posamezni govorec jezika živi. Kontekstualna pogojenost jezika se odraža tudi v folklornem gradivu obmejnih območij (Pisk 2018; Šrimpf Vendramin 2021), ki jih zaznamuje jezikovno mešanje in prepletanje. $\mathrm{V}$ teh prostorih jezik lahko povezuje ali ločuje prebivalce, odločitev za posamezni jezik pa odseva širše družbene in kulturne kontekste 
(Golež Kaučič 2020: 108), hibridne oblike - standardnih ali dialektalnih variant - jezika pa izkazujejo specifične dinamike tega prostora. ${ }^{1}$

Goriška brda ${ }^{2}$ je pokrajina ob slovensko-italijanski meji, na obrobjih katere se historično prepletajo trije jeziki, slovenski, furlanski in italijanski. Različno govoreči prebivalci so do razmejitve po drugi svetovni vojni živeli v istih državnih tvorbah, zato so bili vsakodnevni odnosi med njimi običajni ne glede na jezikovne razlike med njimi. Furlanski zemljiški zakupniki, t. i. koloni, so naseljevali proste 'kolonije' v Brdih, slovenski pa med furlansko govorečo večino; skupaj so služili v vojaških enotah, npr. v 97. tržaškemu pešpolku avstrijske armade, manj premožni so iskali delo kot hlapci in dekle pri samostojnih kmetih ne glede na jezikovno in etnično pripadnost. Medsebojna razmerja so se na politični ravni začela zaostrovati v drugi polovici 19. stoletja, ko je koncept etničnosti postal osrednji organizacijski in mobilizacijski koncept družbe in je jezikovna meja med slovansko in romansko govorečimi etnijami postala pomembna družbena ločnica. Meja med novoustanovljeno Kraljevino Italijo in avstrijsko monarhijo je po letu 1861 še dodatno zaostrila politične napetosti med slovensko in italijansko etnično skupnostjo v Pokneženi grofiji Goriško-Gradiščanski, kamor so Brda spadala. Na željo po javnem manifestiranju etnične pripadnosti v Brdih je vplival tudi referendum 1. 1866, po katerem je sosednja Beneška Slovenija postala del Kraljevine Italije.

Ob etnizirajočih in nacionalizirajočih diskurzih, ki so po letu 1848 prežemali javne razprave $\mathrm{v}$ večjem delu avstroogrskega imperija, kamor je spadalo tudi obravnavano območje, so sobivale nenacionalizirajoče oz. 'vmesne' prakse (Bjork 2008; Zahra 2010; Judson 2016; Van Ginderachter, Fox 2019). Mednje lahko uvrščamo tudi jezikovno heterogene folklorne prakse, na primer petje $\mathrm{v} » n$ enacionalnem « jeziku, petje dvojezičnih pesmi ter uporabo jezikovno mešanih kratkih folklornih oblik.

Josip Tominšek, tajnik Odbora za slovensko narodno pesem v okviru akcije Das Volkslied in Österreich, je leta 1911 poročal, da se ljudstvo na Goriškem »zelo oklepa nedomačih pesmi« (Murko 1929: 42), nad čimer so se pritoževali tudi časopisni dopisniki, ki so npr. poročali, da briška dekleta pojejo pesmi, ki so »furlansko-italijanska godlja brez barve in okusa « (Soča, 16. 9. 1875). Poleg ljubezenskih pesmi, v katerih so erotične teme pogosto zakrili z uporabo nenacionalnega jezika, da bi jih otroci ne razumeli (Pisk 2018, 2020), so se druge pesmi v nenacionalnem jeziku širile predvsem med vojaki in pozneje, ko so Brda po prvi svetovni vojni pripadla Kraljevini Italiji, v šolah z italijanskim učnim jezikom.

Jezikovna heterogenost obravnavanega območja se kaže tudi v nekaterih kratkih folklornih formah, zbranih v Goriških brdih, v katerih se prepletajo kombinacije dialektnih oblik furlanskega, italijanskega in slovenskega jezika $\mathrm{z}$ dialektno prevzetimi besedami in njihovimi modifikacijami. Pregled gradiva je pokazal, da se jezikovna heterogenost najbolj kaže v otroških kratkih folklornih formah, in sicer v zbadljivkah, izštevankah, obrazcih iger

\footnotetext{
1 Raziskava je nastala v okviru projekta Pesemski odsevi medkulturnega sobivanja (J6-9369) in programov Dediščina na obrobjih: novi pogledi na dediščino in identiteto znotraj in onkraj nacionalnega (P5-0408) in Etnološke in folkloristične raziskave kulturnih prostorov in praks (P6-0088), ki jih sofinancira Javna agencija za raziskovalno dejavnost Republike Slovenije (ARSS).

2 Goriška brda ali krajše Brda so v furlanščini poimenovana Cuei, italijansko pa Collio.
} 
in uspavankah. Te kratke folklorne forme so navadno ritmizirane, v ospredju pa ni njihova pripovedna plat, pač pa funkcija, npr. uspavanje, izštevanje, zbadanje, igra itd., a kljub temu jasno odsevajo večjezičnost ljudi, ki so v preteklosti živeli na obravnavanem območju (Makuc 2011; 2021) in ki se do neke mere ohranja še danes (Novak Lukanovič 2011).

Prispevek se tako osredinja na večjezične kratke folklorne oblike, zapisane predvsem kot del otroške folklore v Goriških brdih od prve polovice 20. stoletja pa do zadnjih let. $\mathrm{Na}$ primerih arhivskega in objavljenega gradiva analizirava, $\mathrm{v}$ katerih žanrih kratkih folklornih oblik se pojavlja večjezičnost, kakšna je njegova funkcija in kako se v otroški folklori zrcalijo značilnosti območja. Analiziranim primerom skušava najti vire oz. vzporednice v objavljenem slovenskem in italijanskem gradivu obmejnega območja, hkrati pa gradivo umeščava tudi v raziskave otroške slovstvene folklore na Slovenskem. V središče raziskave dvo- ali večjezičnih folklornih oblik iz Goriških brd postavljava vprašanje, če in zakaj se je večjezičnost najbolj ohranila v kratkih folklornih oblikah in še posebej v otroški folklori.

\section{OTROŠKA SLOVSTVENA FOLKLORA V GORIŠKIH BRDIH}

Kljub navidezni spregledanosti raziskav otrok in otroštva ter otroških folklornih oblik, raziskovalci v slovenskem prostoru tega vprašanja niso zanemarjali (Turk Niskač 2020: 29-30). Nekatera dela se eksplicitno opirajo na otroke in njihovo kulturo (npr. Kuret 1959; Puhar 2004; Turk Niskač 2020), v drugih so tej tematiki posvečena le posamezna poglavja ali pa o življenju otrok beremo zgolj med vrsticami. Etnologinja Mojca Ramšak je ugotavljala, da so raziskovalci najraje preučevali otroško ustno in materialno izročilo skozi analizo različnih virov (npr. dnevnikov, avtobiografij, etnografskih poročilih, fotografij itn.), ki pa so jih večinoma napisali ali uredili odrasli (2007: 33). Folkloristi so bili med prvimi, takoj za zbiralci »ljudskega blaga« iz prve polovice 20. stoletja, ki so se zavedali, da je treba podatke pridobivati tudi od otrok samih (Turk Niskač 2020: 29-30). S tem so jim dali veljavo aktivnih subjektov, ki »sami odločajo in odločijo, kaj ostane v mreži njihovega zanimanja in kaj pade skoznjo v skorajšnjo pozabo« (Stanonik 1984: 86). Tako je že od osemdesetih let 20. stoletja Marija Stanonik s pomočjo šolskih glasil, krožkov, terenskega dela otrok ter poljudnoznanstvenih revij za otroke (npr. Pionir, Pionirski list) zbirala različne žanre slovstvene folklore, od povedk, krajevnih imen, anekdot, pesmic, izštevank, do zbadljivk ipd., ter jih urejene in s komentarji objavljala (npr. Stanonik 1995). Istočasno je spodbujala in mentorirala tudi številne zbiratelje otroške slovstvene folklore (npr. Gašperin 1990, 1998, po Ramšak 2007: 36).

V Goriških brdih se je zbiranje otroške folklore začelo dokaj zgodaj. Že pred drugo svetovno vojno, ko je to območje spadalo pod Kraljevino Italijo, je Milko Matičetov spodbudil zbiranje folklornega gradiva med svojimi sošolci in sogojenci goriškega semenišča (Pisk 2021). V ohranjenih zvezkih prepisov prinesenega mu gradiva so tudi zapisi iz Goriških brd. Izmed dijakov in študentov iz Brd, ki so Matičetovemu predali folklorna izročila svojih rodnih krajev, sta mlada Ladko Lenardič in Albin Sirk prispevala 
tudi nekaj kratkih folklornih oblik, vendar iz Matičetovih zvezkov ni jasno razvidno, ali sta mu folklorne obrazce povedala iz lastne izkušnje ali sta jih zapisala med svojimi rojaki (glej Arhivski vir 1).

Zbiranje folklornega gradiva se je nadaljevalo s sistematičnima akcijama t. i. Orlovih ekip leta 1953 in ekipe Goriškega muzeja leta 1958. V osemdesetih letih 20. stoletja so pod vplivom Janeza Dolenca, profesorja na tolminskem učiteljišču in strastnega zbiratelja slovstvene folklore, na Osnovni šoli Briško-beneški odred Dobrovo učitelji začeli z zbirateljsko akcijo briške folklore (več o Dolenčevem delu med dijaki v Ivančič Kutin 2017: 74; 2018a). Njihov cilj je bil zbrati čim več ljudskih pesmi, ki so se pele med prebivalci Brd, pa tudi drugih oblik folklore, npr. otroške igre, izštevanke, zbadljivke, povedke, spomine in drugo »ljudsko blago«. Zbiranje je potekalo tako, da so učenci med svojimi sorodniki in sosedi zapisali pesmi, učitelji pa so gradivo uredili za objavo v ciklostirani publikaciji Drobci iz kulturne dediščine Goriških brd (Sirk idr. 1980), vse objavljene pesmi pa so bile uvrščene tudi v katalog Glasbenonarodopisnega inštituta ZRC SAZU (GNI R 22.208-GNI $\mathrm{R}$ 22.248). Pozneje so izdali še Otroške igrice in preštevanke (Sirk in Stres b. 1.), ki so uvrščene v katalog GNI R pod številke 22.249-22.292 (Pisk 2018: 117). Zbiranja so se nekajkrat lotili tudi v novem tisočletju, gradivo pa objavili v priložnostnih publikacijah, kot sta Življenje v Brdih nekoč (Kobal idr. 2003) in Kulturna dediščina Brd (Markočič idr. 2019). Že omenjeni iniciator zanimanja za folklorne oblike med učitelji na dobrovski šoli, Janez Dolenc, je leta 1999 objavil popis in drobce gradiva, ki so ga pod njegovim vodstvom zbrali dijaki iz Brd (Dolenc 1999). Nekaj gradiva, predvsem izštevanke in zbadljivke, povzetega tudi po šolskih raziskovalnih akcijah, pa je leta 2009 objavila upokojena učiteljica Darinka Sirk v knjigi Ivanov venec. Gradivo, ki se navezuje na širše obravnavano območje, je bilo zbrano in izdano tudi v okviru projekta Ljudsko izročilo v besedi in glasbi, sofinanciranega znotraj programa Interreg IIIA Italija-Slovenija (2000-2006).

\section{ANALIZA VEČJEZIČNIH KRATKIH FOLKLORNIH OBLIK}

Predhodne raziskave so se posvečale pesemskemu izročilu obravnavanega prostora (Pisk 2018, 2020), zato se v tej raziskavi osredinjava na druge folklorne oblike. Ob pregledu virov se je pokazalo, da se je tudi v otroških folklornih oblikah izražala jezikovna heterogenost območja, zato sva pregledali zgoraj navedene vire ter nekaj dodatnih virov iz širšega raziskovalnega območja. Evidentiranih je bilo približno 50 enot večjezičnih kratkih folklornih form. Čeprav krožijo med odraslimi in otroki različne folklorne forme, pa se je ob pregledu dostopnega gradiva, ki obravnava otroške folklorne obrazce, pokazalo, da se večjezičnost največkrat pojavlja med izštevankami, obrazci iger in uspavankami, torej med kratkimi folklornimi oblikami, katerih primarna funkcija je sicer igra. To ni nenavadno, saj je otroška folklora pogosto relikt drugih folklornih oblik oz. se v njej znajdejo koščki pozabljenih besedil, ki se ohranijo samo v delčkih izven izvorne funkcije in konteksta (Klobčar 2009; Ivančič Kutin 2018b: 212).

Omenjenim in nekaterim drugim kratkim otroškim folklornim formam je skupna rima, saj njen zven in ritem še posebej privlačita majhne otroke. Rima ima zato $v$ 
otroški folklori različne funkcije; tako se razlikujejo rime v uspavankah, besednih igrah, ki jih odrasli govorijo otrokom (npr. Križ kraž Kralj Matjaž, Diči diči ...), in v rimanih besedilih, ki krožijo med otroki samimi. Otroci uživajo v ponavljanju besed, v vzorcih rime in privlačnem ritmu, ki jih spodbudi, da začnejo recitirati rime s starši ter jih pozneje, ko so pripravljeni, pripovedujejo sami (Tucker 2019: 176; Freeman Davidson 2006: 35-36). Rime so torej pogost jezikovni element otroške slovstvene folklore, ki se pojavljajo v različnih oblikah in funkcijah: nekatere so del besedil iger, izštevank, zbadljivk ali kratkih besedil, v drugih je edini namen zabava. Rima pa je tudi tisti jezikovni element, ki je med najbolj značilnimi za večjezične oblike zbranih primerov otroške folklore.

Otroci tako uporabljajo kratke folklorne oblike, v katerih je mogoče zaznati preplet več jezikov, v našem primeru slovenskega in italijanskega, čeprav morda drugega jezika sicer ne znajo, razumejo in ne uporabljajo. Tako so ti jezikovni elementi pogosto uporabljeni zgolj zaradi ritma in rime oz. kot ostanki izvornih oblik.

Zbrano gradivo kljub temu pritrjuje ugotovitvam etnografskih raziskav številnih antropologov, da so otroci opazovalci, imitatorji, igralci in pomočniki, ki avtonomno in samovodeno prevzemajo bit kulture (Turk Niskač 2020: 27). Po ugotovitvah Camille Morelli (2011) so otroci nagnjeni k spontanemu, aktivnemu, praktičnemu učenju, ki jim služi predvsem pri učenju lastne kulture, vendar ne toliko od staršev kot od drugih otrok, zato se v njihovi folklori ohranjajo tudi delčki, ki niso povsem razumljivi. Prek analize razumevanja sveta otroka lahko pridobimo vpogled v širše razumevanje kulture in družbe (Briggs 1992; Turk Niskač 2020: 25). Tako lahko odsev heterogenih jezikovnih praks Goriških brd opazujemo tudi prek folklornih oblik, ki si jih otroci pripovedujejo oziroma jih uporabljajo med igro, torej prek izštevank, zbadljivk, besednih obrazcev iger in uspavank, saj le te pričajo o otrokovem dojemanju sveta in učenju kulture okolice.

\section{1. IZŠTEVANKE}

Med zbranimi večjezičnimi folklornimi enotami iz Goriških brd so najštevilčneje zastopane izštevanke. To so kratka, večinoma ritmizirana besedila, katerih funkcija je izbrati nekoga, ki bo imel vodilno vlogo v naslednji igri (npr. lovljenje, skrivanje ali kaj podobnega). Nekateri raziskovalci, še posebej v 19. stoletju, so izvor izštevank povezovali z žrtvenimi obredi, in sicer naj bi služile za izbor žrtev (Tucker 2019: 175). Tako naj bi bile izštevanke »čarobne forme, ki se v času, ko so opravljale primarno funkcijo, zaradi obrednega pomena niso smele spreminjati. A to prvotno funkcijo so izgubile, prenašanje od ust do ust pa je omogočalo dokaj svobodno spreminjanje teksta (Knific 2006: 38). Folkloristi pa so že v 20. stoletju pomen in smisel izštevank prepoznavali v družbeni dinamiki otrok in diskurzu igre (Tucker 2019: 175). Toda izštevanke so ohranile relativno stabilnost besedilne strukture, saj bi spreminjanje besedila vodilo do tega, da bi bila izbrana druga oseba. Stalna struktura je pomembna tudi zaradi priklica besedila, saj se otroci, še posebej predšolski, zanašajo na to stalnost, ki jim pomaga pri zapomnitvi besedila (Rubin idr. 1997: 421). Analiza rim angleških izštevank je pokazala, da dobesednega priklica besedila ni mogoče pridobiti s pomnjenjem na pamet (Rubin 
1995), ampak pri pomnjenju pomagajo pravila/struktura žanra, ki imajo več omejitev. ${ }^{3}$ To je s shemo usmerjeni priklic (angl. schema-driven recall), pri katerem shema vključuje tudi ritmično in poetično strukturo ter pomen. Poetika izštevank je subtilna in izčrpna, večina besed vsebuje ponavljajoč se zvočni vzorec, ki se doseže s ponavljanjem besed, rim ali aliteracije, vse besede, ki niso vključene v pomen, pa so vključene v enega od teh pesniških postopkov (Rubin idr. 1997: 421). Jezikoslovec John Widdowson je to poimenoval alternativni »trije R « otroške slovstvene folklore - rima, ritem in ponavljanje (angl. rhyme, rhythm and repetition). ${ }^{4}$ Raziskava ameriškega folklorista Kennetha S. Goldsteina je pokazala, da otroci, kljub relativni stalnosti žanra, z namenom izbire tistega, ki ga želijo, prilagajajo sicer ustaljena besedila, tako da dodajajo ponovitve, nove besede, zavlačujejo izgovorjavo itn. (Goldstein 1971; Tucker 2008: 27). Sicer pa se spremembe in variacije besedil najpogosteje pojavijo znotraj rim na način, ki ohranja rimo, ali tam, kjer ne kršijo omejitev (Rubin idr. 1997: 422). V večini izštevank sta ritem in rima, torej zvočna podoba, pomembnejši od pomena, zaradi česar imajo lahko mnogo besedilnih variant, tudi takih, ki vključujejo tujejezične izraze.

Vsi opisani elementi se kažejo tudi v zbranem gradivu. V izštevankah iz Brd se prepletajo predvsem elementi lokalnih govorov slovenskega in italijanskega jezika, pa tudi onomatopejske in nesemantične besedne oblike, ki se pojavljajo predvsem zaradi rime. Težko razumljivo mešanico italijanskih in slovenskih, pa tudi furlanskih narečnih besed je bilo težko zapisati. V večini primerov so zapisovalci neslovenske besede zapisovali fonetično na različne poenostavljene načine, v skladu z njihovo usposobljenostjo.

Obravnavane izštevanke, ki so sestavljene iz prvin več jezikov, sva glede na fonetično sorodnost uvodnih formul in ritmične strukture razdelili v tipe $\mathrm{z}$ več variantami.

\subsubsection{Tip Antele bantele}

Največ variant ima tip s stalnim uvodnim besedilom Antele bantele pepere oz. $\mathrm{z}$ njegovimi manjšimi zvočnimi variantami.

3.1.1.1 Antele bantele / pepele / venti kvatro / venti tre / ara bara specarija / venti kvatro / venti vija. (Kobal idr. 2003)

3.1.1.2. Engele bengele peperè, / vinče quatro, vinče tre, / eris beris špecerija, / vija vaja mularija. (Šmartno) (Sirk 2009: 184)

3.1.1.3. Angele bangele pepere / vinče kvatro vinče tre / eris beris špecarija / vija vaja mularija. (Imenje) (Sirk idr. b. 1.: št. 42)

\footnotetext{
3 Raziskava angleških izštevank je pokazala, da obstajajo omejitve v njihovi variabilnosti z namenom, da si jih otroci lažje zapomnijo ter da se do neke mere ohranja pravičen izbor, kateremu so izštevanke namenjene. Spremembe besedila izštevank se tako največkrat pojavljajo znotraj rime na način, ki ohranja rimo ali na drugih mestih, kjer ne kršijo drugih omejitev. Sicer pa so raziskovalci ugotavljali, da ima žanr shemo, ki vključuje vsaj ponovitev, rimo, aliteracije, obliko štirivrstičnice, vključevanje nesmiselnih besede za celotno rimo ali celo vrstico ter končno stalno besedilo formulo (Rubin idr. 1997).

4 https://www.bl.uk/playtimes/articles/counting-out-games\#.
} 
3.1.1.4. Angele, bangele pepere, / vinče, kvatre, vinče tre, / eris, beris špecerija / vija vaja mularija. (Dolenc 1999: 419)

3.1.1.5 Angule bangule, / vendi Roma, / ke sonjava la korona, / la korona vinči tre, / ke sonjava venti tre. (Sirk 2009: 182)

3.1.1.6. Ara bara ripa re / vinče kvatro vinče tre / eri šperi špecarija / vija vaja la mularija. (Imenje) (Sirk idr. b. 1.: št. 32)

3.1.1.7. Ara bere ripare, / vinče quatro, vinče tre, / eri šperi špicerija, / vija vaja la mularija. (Kožbana) (Sirk 2009: 184)

Variante 3.1.1.1 do 3.1.1.5 so modifikacije izštevanke, zapisane v italijanskem jeziku npr. v Fojdi/Faedis: Andolo bandolo vien di Roma / costodi la mia corona / la corona del re / che sonava ventitré / ventitré di spesiaria / ciapela e marcela via. (Ciceri in D'Orlandi 1960: 16; podobno Gri 1990: 119). V večini variant, z izjemo 3.1.1.5, ki izštevalnega dela nima, je bila zaključna izštevalna formula $v$ italijanščini zamenjana s slovensko »vija vaja mularija«. Ob relativno stabilnem uvodnem delu je zaključni del najbolj podvržen podomačenju, saj mora biti funkcija izštevanja razumljiva vsem udeleženim.

Varianti 3.1.1.6 in 3.1.1.7 sta uvodni vrstici povzeli po varianti istega tipa italijanske izštevanke, zapisane npr. v Poulétu/Paulêt/Povoletto, katere začetek se glasi: Are bare / vin di Rome ... (Ciceri 1960: 15, podobno tudi Mirmina 1960: 21).

Izštevanke s podobno uvodno vrstico, vendar povsem drugačnim nadaljevanjem, so bile zapisane tudi zunaj obravnavanega območja (npr. Gašperin 1988: 37, 43), kar nakazuje na razširjenost uvodne formule Angele bangele (Engule bengule) tako na slovenskem ozemlju kot sorodne Aneghe Taneghe na italijansko govorečem ozemlju. Iz kontekstualnih zapisov o informatorjih, objavljenih v zgoraj navedenih furlanskih in italijanskih revijah, je razvidno, da so bile te izštevanke precej razširjene vsaj od konca 19. stoletja dalje.

\subsubsection{Tip Angele pangele perkurčin}

Podobna fonetična začetna formula je v izštevankah tipa Angele pangele perkurčin, katerih nadaljevanje pa se od prej navedenega tipa razlikuje.

3.1.2.1 Angeli pangeli / pirkučin / čiči biči / Aəmperin / dula vila / vajdi spaka u्रən. (Arhivski vir 2, str. 72)

3.1.2.2 Angele, pangele, perkurčin / čiči biči temperin / Jera, Spaka, Aula / pojdi ven. (Kojsko) (Arhivski vir 1, št. 223, str. 84).

3.1.2.3 Angele pangele perkučiči / čiči biči tampuriči / čika čaka / ư⿱ umies bəraka / tuna vuna / rək u špək. (Kojsko) (Arhivski vir 1, št. 226, str. 85) 
3.1.2.4 Angele pangele / pirkučin čiči bin / čika čaka / vmes koraka / tume vuna / rək u špək. (Na Kalehih, Kojsko) (Arhivski vir 1, št. 422, str. 152)

Variante, ki so bile zapisane večinoma v Kojskem, so v osrednjem delu sorodne izštevanki, zapisani v Vidmu/Udine: Cici bici temperìn / ciche ciachemi sbarache / an te vile nomi spache / fori e cerca. (Ciceri in D'Orlandi 1960: 15), ki je bila v prvi polovici 20. stoletja popularna tudi na širšem italijanskem področju, npr. v Benečiji/ Basso Veneto. ${ }^{5}$

Po zapisih Ivana Kokošarja, skladatelja in zbiratelja pesemskega izročila goriške dežele, so to izštevanko uporabljali pri igri »toč«. Otroci so se postavili v krog in ob tapkanju po dlaneh recitirali izštevanko, preden pa je bila izrečena njena zadnja izštevalna beseda, so se razkropili v teku, otrok, ki ni uspel predati »toča« naprej, pa je lovil (Arhivski vir 3, št. 673).

\subsubsection{Tip Aj baj kome staj}

V primeru izštevanke Aj baj kome staj, katere začetek ritmično spominja na v širšem slovenskem prostoru znano izštevanko An ban pet podgan (npr. Knific 2006: 38), gre za fonetično modificirano italijansko izštevanko. Podobno kot v italijanskih izštevankah, $\mathrm{v}$ katerih je osnovni pomen besed podrejen rimi, ritmu in funkciji, tudi obravnavana izštevanka, ki se sicer začne z italijansko vljudnostno frazo »Come stai? «(slv. Kako si?), vsebuje le malo pomenskih besed (Cantarutti 1956: 28). Modifikacije in medjezikovna prepletanja so najbolj vidna $\mathrm{v}$ zaključnem delu, v katerem se stalne izštevalne formule lahko smiselno zamenjujejo.

3.1.3.1. Aj baj kome staj, / ije bije kompanije, / cimu rakum tikum takum, / aj baje ej bumf. (Sirk 2009: 182)

3.1.3.2 Aj baj, kome staj? / Ija bija, kompanija. / Ciribakul, tikul takul. / Vija, vaja, ven. (Kobal idr. 2003)

3.1.3. 3 Aj baj kome staj / ije bije kompanije / cimu raku tike taku / aj bej ej bumf. (Sirk idr. b. 1.: št. 25)

\subsubsection{An baj / kome staj? / Ari mari / muš ti ven. (Markočič idr. 2019)}

Primera 3.1.3.1 in 3.1.3.3 neposredno izhajata iz italijanske izštevanke, razširjene v sosednji Furlaniji Julijski krajini, npr. Ai bai / come stai, / tie mie / compagnie, / samiraco / tico taco, / ai bai / buf (Cantarutti 1956: 28), ki pa je bila v nespremenjeni obliki zapisana tudi v Ankaranu (Gašperin 1988: 33). Varianta 3.1.3.2 je v zaključku prevzela splošno slovensko izštevalno formulo »vija, vaja, ven«. Variante s splošno znanim

\footnotetext{
5 Conte, tiritere e filastrocche del territorio del Basso Veneto, anni “30-50". https://issuu.com/emozionando/ docs/pite_pite_coche_tiritere_filastrocche_e_tradizion
} 
slovenskim zaključkom »Vija, vaja, ven« lahko razumemo kot najmlajšo fazo razvoja oz. kot kontaminacijo starejšega lokalnega izročila s splošno slovenskim, priučenim skozi izobraževalni proces ali različne medije. Podobno, tj. jasno izštevalno funkcijo, ima tudi slovenski zaključek primera 3.1.3.4, ki je sicer krajša in modificirana oblika druge variante navedene izštevanke, ki se v italijanščini glasi: Ai bai / tu mi stai / tie mie / compagnie / San Miracco / ticco-tacco / ai bai bin buf / ari mari mus. ${ }^{6}$

\subsubsection{Tip Ana bana}

$\mathrm{V}$ naslednjih izštevankah se pojavlja uvodna formula, znana tudi v izštevankah iz furlansko-italijanskega prostora, npr. Ane bane! tiche tane / sie mie / compagnie / uz buz! laudi struz. (Querzola 1991: 25).

3.1.4.1 Ana bana / tuta bana / v prvi klopici sedi / ima torbico pri sebi / pojdi ven ti! (Sirk idr. b. 1.: št. 4)

3.1.4.2 Ana bana dindarana / štruklja kuha dindaranen / bana ti pa pojdi ven. (Sirk idr. b. 1.: št. 8)

3.1.4.3 Ana bana, tuta bana / erne ša, erne va / štirka fajfa trla ton / tista baba pojde von! (Sirk idr. b. 1.: št. 27)

\subsubsection{Druge večjezične izštevanke}

V sledečih izštevankah, zapisanih v Brdih, prepoznamo nekatere italijanske ali furlanske besede ali besedne zveze, vendar zaenkrat neposredni izvor v določenih italijanskih ali furlanskih izštevankah ni bil prepoznan.

3.1.5.1 On tron tronta si, / si vi kompari, / al baraka tika taka, / vija vaja ven. (Sirk 2009: 183)

3.1.5.2 Ine one $\mathrm{u} /$ kapitale $\mathrm{u} /$ cika bela $\mathrm{u} /$ trimf tram trum. (Sirk idr. b. 1.: št. 30)

3.1.5.3 Oneri doneri / krispa le / si kipa kapa / šubla sabla / Jermen termen / Hrast. (Arhivski vir 2; str. 21)

Zapisana pa je bila tudi izštevanka, ki je vsebovala sestavine iz treh jezikov: razširjeno nemško uvodno formulo »Ajns, cvaj, draj« (»En, dva, tri«), slovensko osrednje besedilo in italijanski izraz za plačilno sredstvo »činkve šoldi« (»pet denarjev«). Besedilo izštevanke odseva podobe življenja v habsburški monarhiji, ko se je v Gorici in celotni deželi poleg italijanskega in slovenskega jezika uporabljal tudi uradni jezik nemščina.

${ }^{6}$ https://www.filastrocche.it/nostalgici/cont/aibai.htm. 
3.1.5.4 Ajns cvaj draj, / po cesti gre tramvaj. / Smo dali činkve šoldi / ne dajo več nazaj. (Markočič in drugi 2019)

\subsection{ZBADLJIVKE}

Zbadljivke so folklorne oblike, katerih primarni namen je zbadanje, zasmehovanje, provokacija ali norčevanje iz duhovnih, socialnih in družbenih pomanjkljivosti posameznikov. Zbadljivke se sicer lahko pojavijo v več različnih oblikah. Po dolžini so lahko daljše ali krajše, po jezikovni plati pa so lahko v prozni ali ritmizirani obliki (npr. šaljive zgodbe, šale, daljše in krajše šaljive pesmi, kratke ritmizirane paremioške enote in vzdevki) (Šrimpf Vendramin 2019; 2021). Zbadljivke so na Slovenskem zbirali in analizirali predvsem ob raziskovanju otroške folklore (glej Merhar 1956: 108; Knific 2006: 38; Stanonik 1999: 94; 2006: 259), vendar zbadljivke niso (bile) izključna domena otrok.

Kljub temu da se zbadljivke po obliki in dolžini močno razlikujejo, pa je vsem skupna funkcija zbadanja, smešenja, zasmehovanja, lahko tudi žaljenja ali zmerjanja. Nekatere zbadljivke, ki se navezujejo na medsosedske odnose ali na določene značilnosti ali osebnostne lastnosti prebivalcev, kot npr. »meščani, hudobni psi, lažnivci, jokci« (Tschinkel 2004: 187-188), so (bile) del otroške folklore, a so bili njihovi avtorji in govorci večinoma odrasli (Terseglav 1990: XIV), otroci pa so jih le ponavljali (Šrimpf Vendramin 2019). Podobno smemo domnevati tudi za kratke oblike zbadljivk, zapisanih v Brdih:

3.2.1 Italjan madža pan, mandža repa, dopo krepa. ${ }^{7}$

3.2.2 Ai un bel sorizo, ma niməš ne paštu ne rizo. (Zuljan Kumer 1999: 45)

3.2.3 Polenta kontenta / formadi per grata / Pina ričota / Bepi soldat. (Markočič in drugi 2019)

3.2.4 Tona bona / čul de fjar / la prasica / sub brjar / la prasica / ščampafur / Tona bona / kur da ur. (Sirk in drugi b. 1.; št. 37)

Zbadljivki 3.2.1 in 3.2.2 bi lahko sodili v polje politične satire: prva odraža obdobje mednacionalnih sporov med Slovenci in Italijani za dosego političnih pravic, druga pa sega v čas po drugi svetovni vojni, ko so se uveljavljala določila pariške mirovne pogodbe in je bil na slovenski strani uveden vojaški nadzor Jugoslovanske ljudske armade nad novo začrtano mejo. Ta zbadljivka, ki je izražala nezadovoljstvo dela lokalnega prebivalstva, je bila naslovljena predvsem na neslovensko govoreče predstavnike nove oblasti, ki niso razumeli lokalnega govora, pomešanega $\mathrm{z}$ italijanskimi frazami. ${ }^{8} \mathrm{Zbadljivka} 3.2 .4$ pa sodi v tip zbadljivk osebne narave, ki z vključevanjem furlanskih izrazov zakriva zbadanje posameznih deklet in njihovega domnevnega početja med plesom na brjajih. ${ }^{9}$

\footnotetext{
7 Povedal Branko Marušič, 2020. Prost prevod: »Italijan je kruh, je repo, potem pa crkne.«

8 Intervju Golo Brdo; 10. 11. 2007. Prost prevod: »Imaš lep nasmeh, ampak nimaš ne testenin ne riža.«

9 Leseno plesišče, ki so ga Brici večinoma najemali v Furlaniji.
} 


\subsection{BESEDILNI OBRAZCI IGER}

Folklorni besedilni obrazci so tudi del iger, kot na primer iger lovljenja ali tekanja (npr. Kdo se boji črnega moža?, gnilo jajce ipd.). Tako so bili večjezični folklorni obrazci zabeleženi tudi kot del nekaterih otroških iger, ki so se jih igrali otroci v Goriških brdih. Ena od takšnih iger je igra korakanja, kjer dva otroka, ki se držita tesno skupaj, korakata in ob tem izgovarjata besedilni obrazec, ob koncu besedila pa spreminjata smer.

\subsubsection{Sipuli si / sipuki sa / Anca špara / džiro di kva. (Sirk idr b. 1.: št. 45)}

\subsubsection{Sipuku si, / supuku sa, / vojna špada, džiro di qua. (Sirk 2009: 183)}

Primera domnevno izhajata iz plesov na priljubljeno skladbo Magic Moments ${ }^{10}$, ki je po izidu leta $1957 \mathrm{v}$ italijanski različici postala popularna med briškimi mladimi plesalci. ${ }^{11}$ Ta je vključevala tudi parlando

Sun chi de per mì / in d'la vasca da bagn / cul bigul a gala. // Me giri de chi, / me giri de la, / (ahi!) me schisci una bala,

ki se je v okrajšani in modificirani obliki ohranil kot osnova otroške igre.

Drugo ohranjeno besedilo igre, ki po uvodu spominja na znano rajalno igro Ringa ringa raja, ki pa v nadaljevanju preide v lokalne govore italijanskega jezika:

Ringa ringa raja / Martina šu la paja / paja pajuca / Peter kukuluca. (Arhivski vir 2; str. 21)

Tukaj gre najverjetneje za prilagojeno besedilo za otroško igro, ki so jo otroci igrali tako, da je glavni igralec v svojo pest ob koncu besedila igre poskušal ujeti čim več kazalcev drugih otrok, ki niso uspeli pravočasno umakniti prsta (Budal 1950: 360). Igra je bila znana tudi med otroki v okolici Gorice, kjer so ob izvajanju govorili sledeče besede: »Ghiri, ghiri, gaia / San Martin di paia (paglia) / paia, paiuzza (paglia, pagliuzza) / ciappi la Mariuzza!« (Budal 1950: 360).

\subsection{USPAVANKE}

Katarina Juvančič, ki se je v slovenskem prostoru prva poglobljeno ukvarjala s preučevanjem uspavank, je ugotavljala, da gre pri tem folklornem žanru za »'prave' pesmi ali pa za improvizirano skladanje besedil, napevov, ritmičnih verzov ali melodičnega govora, ki nastaja v danem položaju « (Juvančič 2009: 277). Kot uspavanka je tako lahko razumljena vsaka pesem oziroma glasba, ki je uporabljena v namen pomirjanja in uspavanja otroka (ali odraslega). $\mathrm{V}$ ta namen so se in se še uporabljajo zelo raznovrstne pesmi: tako ljudske (npr. balade, ljubezenske pesmi, žalostinke, ženitne pesmi, celo napitnice) ali popularne pesmi (domače ali tuje) kakor tudi instrumentalna glasba (Juvančič 2009: 277). Ker je glavna funkcija uspavank to, da otrok čimprej zaspi, sta pomembna predvsem njena

\footnotetext{
${ }^{10}$ Glasba Burt Bacharach, besedilo Hal David, izvajalec Perry Como.

${ }^{11}$ Informacije pridobljene med terensko raziskavo Marjete Pisk v Goriških brdih (2007).
} 
monotona ritem in melodija. Semantična plat je v uspavankah drugotna, zato so pogosto uporabljene stalne nesemantične fraze, npr. nina nana, aja tutaja ipd.

Uspavanke pa tako, kot ostali folklorni žanri, ki jih spoznavamo v otroštvu, odsevajo med drugim tudi proces inkulturacije v skupnost, v katero smo rojeni. Tako jih lahko razumemo kot »kulturni kod, napolnjen s »sekundarnimi« konotacijami in pomeni (spolnimi, ideološkimi, političnimi, zgodovinskimi ipd.), odvisno od okoliščin, v katerih jih dokumentiramo, in okoliščin posameznikovega življenja (Juvančič 2009: 281). Zato ne preseneča, da so se v Brdih pele tudi povsem italijanske uspavanke.

3.4.1 Nina nana / levin pinpin / e la mama / qua vicin. / Il papa že anda lontan / ma non viene fin doman. (Arhivski vir 2)

3.4.2 Din don kampanon, / kje si kosu, kje si jow? / Dol pər teti Tinci / in botri Katerinci, / kjer belo moko sejejo, / velike hlebe delajo. / Je pəršla botra mati, / me je tela pokopati. (Devetak 2007: 155)

3.4.3 »Din, don, šjor beron! / Ki si kuosu, ki si jaw?«/ »Štir gəlobce səm pojaw. / Jə pršla buotra mati, / m je tiela oklofati. / Səm teku po ni ciesti, / so me tieli pəsi sniesti, / səm skočnu čez en zid, / səm najdu u karti bonč zəvit.« (Devetak 2007: 156)

Uspavanka 3.4.1, ki jo je etnomuzikolog Radoslav Hrovatin med terenskim raziskovanjem t. i. Orlovih ekip v Brdih poleti 1953 zapisal (z manjšimi nedoslednostmi) v italijanskem pravopisu, v italijansko besedilo pomensko smiselno vključi slovenski izraz 'že'. Modifikacija je verjetno nastala zaradi pozabljenega ali ne povsem razumljivega italijanskega besedila in potrebe, da se zgodba smiselno nadaljuje. Podobna uspavanka, ki ima z zapisano verjetno skupni vir, je bila znana v širšem italijansko govorečem okolju, tudi v Dalmaciji. ${ }^{12}$ Varianti 3.4.2 in 3.4.3 sta nastopali v več funkcijah, npr. kot uspavanki, otroški rimi ter oponašanje zvonov in sta v mnogoterih variantah znani v slovenskih, furlanskih in italijanskih dialektih širšega obravnavanega območja (npr. Cararra 1935: 196; Querzola 1991: 120). Preprosta in poudarjena ritmična shema omogoča, da besedilo, ki se v vseh jezikovnih variantah začne podobno »Din-dòn, campanòn«, v nadaljevanju variira $\mathrm{v}$ številne variante, ki pa v primeru, ko se pojejo kot uspavanke, le malo modificirajo enostavno melodijo.

\section{SKLEPNE UGOTOVITVE - OTROŠKA FOLKLORA KOT ODSEV (VEČJEZIČNEGA) SVETA}

Analiza kratkih folklornih oblik s sestavinami več jezikov, zapisanih v Goriških brdih, je pokazala, da se največ od njih uvršča med otroško folkloro. To ne preseneča, saj se določene

\footnotetext{
${ }_{12}$ Nanà, nanà, nanetta / mi mama no la ghé / la xe a messa. / Nanà, nanà, nanetta / papà le xe lontan / nanà, nanetta. / Nana mio bambin / tu sei piccinin / nana mio bambin. (Dalmacija. Zapisal Giorgio Nataletti, harmoniziral Antonio Ferdinandi), https://dinamico2.unibg.it/mabg/ninnananna1934.pdf
} 
folklorne zvrsti in oblike pogosto znajdejo med otroško folkloro na zadnji stopnji, preden izginejo iz kolektivnega spomina in rabe. Izumiranje določene šege ali izgubljanje ritualnega pomena vodi namreč v tipološka prehajanja (Klobčar 2009: 178), zato so nekatere oblike folklore dejansko sodobne modifikacije preteklih oblik in žanrov. Poleg tega so te folklorne oblike, če so se ohranile med otroki, raziskovalci uvrstili v polje otroške folklore (prim. Ramovš 1991) ne glede na njihovo siceršnjo pojavnost in razširjenost.

Tako kot jezik je tudi folklora ogledalo kulture in vključuje v različnih oblikah, tudi v slovstveni folklori, drobce verovanj, prepričanj, obredov, družbenih struktur in tehnologij ter opise življenja posamezne družbene skupine (Bascom 1954: 337). Folklora odraža načine življenja skupnosti, otroška folklora pa odraža tudi družbo odraslih, njihove skrbi, pomembne dogodke lokalne skupnosti, kot tudi širše družbeno dogajanje. Tako so raziskovalci v zadnjih desetletjih ugotavljali, da otroci odmeve velikih dogodkov, ki zaznamujejo njihovo skupnost, prenesejo tudi v lastno igro in folkloro (Tucker 2008: 7-9).

Otroška folklora določenega območja razkriva ne samo specifike sodobne družbe, ampak posredno, preko izročila, tudi njene izumrle ali pozabljene šege in folklorne oblike. Otroška igra in folklora namreč odsevata svet odraslih, družbene strukture in vrednote (Turk Niskač 2020: 38), saj otroci preigravajo tisto, kar lahko opazujejo v svojem vsakdanjiku, a hkrati elemente spreminjajo ter jim dajejo svoje pomene in interpretacije. Zato otroška igra in folklora nista nikdar enostavna in mehanska reprodukcija dejavnosti odraslih, ampak vedno domišljijska konstrukcija, osnovana na temah iz odraslega življenja in življenja starejših otrok (Meyer Fortes 1938: 59). Otroško igro moramo zato razumeti kot dvosmerni proces, kajti »V otroški igri se odražajo družbeno okolje in njegovi vplivi, hkrati pa otroci z igro to družbeno okolje raziskujejo, spreminjajo in preoblikujejo« (Turk Niskač 2020: 39), kar lahko opazujemo tudi v kratkih otroških folklornih oblikah, zapisanih v Goriških brdih.

Otroške folklorne oblike, zapisane v Goriških brdih, torej jasno kažejo na jezikovne prakse obmejnega območja, ki so bila in so še vedno območja posebnih dinamik (Haller, Donnan 2000; Wilson, Donnan 2012; Wilson 2012; Lechevalier, Wielgohs 2013; Köstlin 2017), pa tudi heterogenih ljudskih tradicij. Tako tudi predstavljeni primeri (otroških) večjezičnih kratkih folklornih oblik, zabeleženih v Goriških brdih, kažejo na heterogenost kulturnih praks in povezanost območja, ki presega nacionalne meje in se jasno odraža tudi $\mathrm{v}$ folklori, kot na primer mešanje slovenskih in italijanskih besed (pogosto v modificirani obliki) v zbadljivkah, razširjenost italijanskih začetnih formul izštevank med briškimi otroki, petje italijanskih uspavank itn.

Te heterogenosti kulturnih praks na obmejnem območju so se zavedali že raziskovalci, združeni v neformalno delovno skupnost narodopiscev vzhodnoalpskih dežel Alpes Orientales, ki je delovala v desetletjih po drugi svetovni vojni ter je nastala kot odmev na spoznanje Milka Matičetovega, da je ljudska kultura tega območja sorodna mimo geografskih, upravnih in političnih meja (Fikfak in Kuret 2008: 77; Pisk 2017: 111) in zato ne more biti raziskovana samo znotraj posameznih nacionalnih in jezikovnih meja, ampak širše.

Kljub drugačni naravnanosti narodnih aktivistov in zbiralcev »narodnega blaga« v 19. stoletju pa se je izkazalo, da v obmejnih področjih, posebej pri žanrih, ki niso nacionalno reprezentativni, vprašanje jezika ni osrednjega pomena za nosilce folklornih tradicij, pač pa se ti funkcijsko določeni žanri stapljajo z lokalno zvočno krajino (Pisk 2020). Če se 
besedila ljudskih pesmi, ki so sinkretična celota melodije in besedila, skupaj z ritmično shemo bolj nagibajo h knjižnemu jeziku (Golež Kaučič 2020: 109), pa je pri dvo- ali večjezičnih folklornih oblikah, zapisanih v Goriških brdih, drugače. V njihovo strukturo se knjižne oblike (tako slovenskega kot italijanskega jezika) le redko inkorporirajo, pač pa večina besednih oblik ostaja znotraj koda lokalnih govorov in onomatopije. Posamezne ustaljene slovenske oblike, npr. v izštevankah, pa so se med otroki oblikovale in ohranile predvsem pod vplivom raznih knjižnih objav, ki so povezane z vzgojnimi in učnimi programi v vrtcih in osnovnih šolah (Knific 2006: 38). V procesu spreminjanja družbenih in kulturnih razmer se spreminjajo tudi oblike otroške folklore, prisotne v Goriških brdih. Kljub nacionalizirajočim poskusom folklornega diskurza, ki je v določenih obdobjih 19. in 20. stoletja poudarjalo jezikovno čistost folklornih oblik (Pisk 2013), pa so - predvsem v otroški folklori - še vedno prisotne tudi jezikovno heterogene kratke folklorne oblike, ki odsevajo tesno prepletenost sveta in ljudi ob jezikovni in državni meji.

\section{VIRI IN LITERATURA}

Babič, Saša, 2019: Obravnava folklornih obrazcev v osnovnošolskih berilih in revijah. Jezik in slovstvo 64 (2), 19-30, 115.

Bascom, William R., 1954: Four Functions of Folklore. The Journal of American Folklore 67 (266), 333-349.

Bjork James E., 2008: Neither German nor Pol: Catholicism and National Indifference in a Central European Borderland. Ann Arbour: University of Michigan Press. DOI: 10.3998/ mpub. 217738

Budal, A., 1950: Iz otroškega življenja v Štandrežu pri Gorici. Slovenski etnograf. 3/4, 358-360.

Briggs, Jean L. 1992: Mazes of meaning: How a child and a culture create each other. New directions for child development 58, 25-49. DOI: https://doi.org/10.1002/cd.23219925804

Cantarutti, Novella, 1956: Filastrocche e cantilene. Sot la nape 8 (5-6), 27-29.

Carrara, Dolfo, 1935: Filastrocche infantili goriziane. Bollettino della Società filologica friulana Ce fastu? 11 (7-10), 196-198.

Ciceri, Andreina in Lea D'Orlandi, 1960: »Conte« per giochi infantili. Sot la nape 12 (2), 11-16.

Devetak, Viljena (ur.), 2007: Je žalostna, ma je liepa ta pesem. Ljudsko izročilo v besedi in glasbi. Gorica: Kulturni center Lojze Bratuž.

Dolenc, Janez, 1999: Briški dijaki v Tolminu - zapisovalci briških ljudskih izročil. Briški zbornik 1999, 418-432.

Fikfak, Jurij in Niko Kuret, 2008 (1985): Pogovor. V: Ingrid Slavec Gradišnik in Helena Ložar Podlogar (ur.), Čar izročila: Zapuščina Nika Kureta (1906-1995). Ljubljana: Založba ZRC, 69-80.

Fortes, Meyer, 1938: Social and psychological aspects of education in Taleland. Africa 11 (S4), 5-64.

Freeman Davidson, Jane Ilene, 2006: Language and Play: Natural Partners. Doris Pronin Fromberg in Doris Bergen (ur.), Play from Birth to Twelve: Contexts, Perspectives, and Meanings. New York: Routledge, 31-40.

Gašperin, Roman, 1990: Enci benci na kamenci: slovensko otroško izročilo. Lesce: Osnovna šola F. S. Finžgarja. 
Gašperin, Roman, 1998: Enci benci na kamenci 2: slovensko otroško izročilo. Ljubljana: Mladinska knjiga.

Goldstein, Kenneth S., 1971: Strategy in Counting-Out: An Ethnographic Folklore Field Study. Elliott M. Avedon and Brian Sutton-Smith (ur.), The Study of Games, New York: John Wiley and Sons, 167-178.

Golež Kaučič, Marjetka, 2020: Singing the other: singing in two languages and code-switching/ stitching. Tautosakos darbai 59, 100-119.

Gri, Pier Giorgio, 1990: Gli informatori e i folkloristi: Pia De Luca e Lea D'Orlandi. Ce fastu?66 (1), 99-126.

Haller Dieter, Hastings Donnan, 2000: Borders and Borderlands: An Anthropological Perspective. Ethnologia Europaea 30 (2).

Ivančič Kutin, Barbara, 2017: Motivne značilnosti pripovedi o izginulih jezerih na Tolminskem. Glasnik SED 57 (1/2), 74-85.

Ivančič Kutin, Barbara, 2018a: Pomen dijaškega arhiva Janeza Dolenca za folkloristične in druge domoznanske raziskave. Goriški letnik 42, 303-310.

Ivančič Kutin, Barbara, 2018b: Zagovori v terenskih zapisih iz Benečije. Slovenistika in slavistika v zamejstvu. Videm: [Slovenski slavistični kongres, Videm, 27.-29. september 2018], 207-220.

Ivančič Kutin, Barbara., 2015: Molitvice, ki jih danes še najdemo v Benečiji (Prosnid, Viškorša, Dreka, Kraj). Trinkov koledar za Beneške Slovence za leto 2015, 164-173.

Judson, Pieter M., 2016: Nationalism and Indifference. Johannes Feichtinger, Heidemarie Uhl (ur.), Habsburg neu denken. Vielfalt und Ambivalenz in Zentraleuropa. 30 kulturwissenschaftliche Stichworte. Wien: Böhlau, 148-155.

Juvančič, Katarina, 2009: Ko se prebudijo »nine nane« in »aje tutaje«: etnomuzikološke raziskave uspavank. Traditiones 38 (1), 275-286. DOI: https://doi.org/10.3986/Traditio2009380118

Klobčar, Marija, 2009: Christmas songs and constructing identities. Traditiones 38 (1), 173-188.

Knific, Bojan, 2006: Izštevanke in zbadljivke. Folklornik 5, 38-42.

Kobal Uroš et al., 2003: Življenje v Brdih nekoč: priložnostno glasilo učencev 2.a in 2.b devetletne osnovne šole. OŠ Dobrovo: Dobrovo.

Köstlin, Konrad, 2017: Vanishing Borders and the Rise of Culture(s). Ethnologia Europaea 47 (1), https://doi.org/10.16995/ee.1226.

Kuret, Niko, 1959: Igra in igrača v predšolski in šolski dobi. Maribor: Obzorja.

Lancy, David F., 2016: Teaching: Natural or Cultural? David C. Geary, Berch, Daniel B. (eds.), Evolutionary Perspectives on Child Development and Education. Cham: Springer International Publishing, 33-65. DOI: https://doi.org/10.1007/978-3-319-29986-0_2

Lechevalier Arnaud, Wielgohs Jan (ur.), 2013: Borders and Border Regions: Changes, Challenges and Chances, Bielefeld: Transcript Verlag, https://www.jstor.org/stable/j.ctv1fxhcq.

Makuc, Neva, 2011: Historiografija in mentaliteta v novoveški Furlaniji in Goriški. Ljubljana: Založba ZRC, ZRC SAZU.

Makuc, Neva, 2021: Border Identities in the Early Modern Period: Venetian Friuli and the Habsburg County of Gorizia mirrored in contemporary historiography. Berlin: P. Lang, cop.

Markočič, Helena et. al., 2019: Kulturna dediščina Brd. Raziskovalna naloga, šolsko leto 2018/2019. OŠ Alojza Gradnika Brda.

Merhar, Boris, 1956: Ljudska pesem. Lino Legiša in Alfonz Gspan (ur.), Zgodovina slovenskega slovstva. Ljubljana: Slovenska matica, 31-114.

Mirmina, Emilia, 1960: Contis infantili raccolte a Paularo. Sot la nape 12 (1), 21. 
Morelli, Camilla, 2012: Teaching in the rainforest: Exploring Matses children's affective engagement and multisensory experiences in the classroom environment. Teaching Anthropology 2, 53-65.

Murko, Matija, 1929: Velika zbirka slovenskih narodnih pesmi z melodijami. Etnolog 3, 5-54.

Novak Lukanovič, Sonja, 2011: Language diversity in border regions: Some research data on the perception among the pupils of two secondary schools. Annales 21 (1), 79-92.

Pisk, Marjeta, 2013: Nacionalizacija ljudske pesemske tradicije Goriških brd = Nationalizing the folksong tradition of Goriška brda. Prostor v literaturi in literatura v prostoru $=$ Space in literature and literature in space 60 (3), 483-498, 499-515.

Pisk, Marjeta, 2017: Družbene mreže v folklorističnem raziskovanju. Traditiones 46 (3),103-121.

Pisk, Marjeta, 2018: Vi čuvarji ste obmejni: pesemska ustvarjalnost Goriških brd v procesih nacionalizacije kulture. Ljubljana: Založba ZRC, ZRC SAZU.

Pisk, Marjeta, 2020: Language switching in (folk) songs along the Slovenian-Italian border. Tautosakos darbai $=$ Folklore studies 60, 79-93.

Pisk, Marjeta, 2021: Predvojni zapisi ljudskih pesmi Milka Ukmarja (Matičetovega). [v tisku].

Puhar, Alenka, 2004: Prvotno besedilo življenja. Ljubljana: Studia humanitatis.

Querzola, Rita, 1991: Filastrocche raccolte nella valle del Bût. Ce fastu? 67 (1), 117-128.

Ramšak, Mojca, 2007: Etnološko preučevanje otrok v slovenski etnologiji in folkloristiki. Etnolog $17=68,31-41$.

Ramovš, Mirko, 1991: Otroške igre z odvzemanjem in privzemanjem na Slovenskem. Traditiones 20, 127-142.

Rubin, David C., 1995: Memory in oral traditions: The cognitive psychology of epic, ballads, and counting-out rhymes. New York, Oxford: Oxford University Press.

Rubin, David C., Violeta Ciobanu, William Langston, 1997: Children's memory for counting-out rhymes: A cross-language comparison. Psychonomic Bulletin \& Review 4, 421-424.

Sirk, Darinka, 2009: Ivánov venec: briške šege in navade. Dobrovo: samozaložba.

Sirk, Darinka, Peter Stres (ur.), [b. 1.]: Otroške igrice in preštevanke. Goriška Brda: raziskovalna naloga. Dobrovo: OŠ Briško - Beneški odred.

Stanonik, Marija, 1995: Slovstvena folklora v očeh današnjih mladoletnikov: analiza nalog s tekmovanja za Cankarjevo priznanje za leto 1993. France Novak, Kranjc Simona (ur.), Zborovanje slavistov, Celje, 1993. Ljubljana: Zavod Republike Slovenije za šolstvo in šport. (Zbornik Slavističnega društva Slovenije; 4), 107-123.

Šrimpf Vendramin, Katarina, 2019: »Medanc podklanc je figo zagledal, je mislil, da je žganc«: oblike, vsebina in funkcija medkrajevnega zbadanja na Slovenskem. Glasnik Slovenskega etnološkega društva 59 (2), 92-102.

Šrimpf Vendramin, Katarina, 2021: Zgodbe in prostor: Ustno izročilo in kolektivni spomin v zgornjem Obsotelju. Ljubljana: Založba ZRC, ZRC SAZU

Stanonik, Marija, 1999: Slovenska slovstvena folklora. Ljubljana: DZS (Zbirka Klasje).

Stanonik, Marija, 2006: Procesualnost slovstvene folklore: Slovenska nesnovna kulturna dediščina. Ljubljana: Založba ZRC, ZRC SAZU.

Terseglav, Marko, 1990: Reškova zbirka šaljivih pesmic. Dušan Rešek (ur.), Strijc so strino: Šaljive in erotične ljudske pesmi iz Prekmurja. Murska Sobota: Pomurska založba, 1990, IX-XVIII.

Tschinkel, Wilhelm, 2004: Kočevarska folklora: V̌̌egah, navadah, pravljicah, povedkah, legendah in drugih folklornih izročilih. Ljubljana: Založba ZRC, ZRC SAZU.

Tucker, Elizabeth, 2008: Children's Folklore: A Handbook. Greenwood Publishing Group. 
Tucker, Elizabeth, 2019: American Folk Poetry. Simon J. Bronner (ur.), The Oxford Handbook of American Folklore and Folklife Studies. New York: Oxford University Press, 176-189.

Turk Niskač, Barbara, 2021: O igri in delu: antropologija zgodnjega otroštva. Ljubljana: Založba ZRC, ZRC SAZU.

Van Ginderachter Maarten, Fox Jon (ur.), 2019: National Indifference and the History of Nationalism in Modern Europe. New York: Routledge.

Vygotski, Lev Semenovitch, 1967: Thought and language. Cambridge: The M. I. T. Press.

Wilson Thomas M. 2012. The Europe of Regions and Borderlands. Ullrich Kockel, Máiréad Nic Craith, Jonas Frykman, Malden (ur.): A Companion to the Anthropology of Europe. Malden, MA: Wiley Blackwell, 163-180.

Wilson Thomas M., Hastings Donnan (ur.), 2012: A Companion to Border Studies, Malden, MA, Oxford, UK: Wiley Blackwell.

Zahra Tara, 2010: Imagined Noncommunities: National Indifference as a Category of Analysis, Slavic Review 69 (1), 93-119.

Zuljan Kumer, Danila, 1999: Govor Golega Brda. Briški časnik 4 (14), 45.

\section{ARHIVSKI VIRI:}

Vir 1: Arhiv GNI ZRC SAZU, Štrekljeva zapuščina 98. Milko Matičetov: Narodne pesmi 1.

Vir 2: Arhiv GNI ZRC SAZU, Terenski zvezek III., Brda, R. Hrovatin.

Vir 3: Arhiv GNI ZRC SAZU, Kokošarjeva zapuščina, Kokošar 12, mapa 2.

\section{MULTILINGUAL SHORT FOLKLORE FORMS: EXAMPLES FROM THE GORICA HILLS \\ Marjeta Pisk, Katarina ŠrimpF Vendramin \\ $\infty$}

Language is not only a tool for communication, but it is strongly interwoven with culture, society, natural resources, and the environment in which an individual language speaker lives. The contextual conditionality of language is also reflected in the folklore material of the borderlands, which is characterized by linguistic mixing and interweaving. Goriška brda (Gorica Hills), a region along the Slovenian-Italian border, is an area where three languages, Slovenian, Friulian and Italian, have historically intertwined. Until the border was drawn after the Second World War, Slovene-speaking and Friulian-speaking inhabitants lived in the same state, so everyday relations between them were normal, regardless of the linguistic differences between them. The multilingual practices of the inhabitants are also reflected in folklore genres.

The article focuses on multilingual short folklore forms, written down mainly as a part of children's folklore in Goriška brda, from the first half of the 20th 
century until recent years. On the basis of the examples of the collected material, it is presented in which genres of the short folklore forms multilingualism appears, what function it has and how the peculiarities of the area are reflected in the children's play.

The review of the existing material has shown that most bilingual or even trilingual units of literary folklore from Goriška brda are to be found among children's folklore, among counting-out rimes, jears and play texts, i.e. among short folklore forms whose main function is play.

Numerous anthropologists have found, on the basis of ethnographic research, that children are observers, imitators, actors and helpers who acquire the essence of culture independently and automatically. Folklore forms that children narrate or use during play also show us something about the child's perception of the world and learning about the surrounding culture.

Many forms of children's folklore have rhyme, as its sound and rhythm are particularly attractive to young children. Rhymes are therefore a common linguistic element of children's folklore and occur in a variety of forms and functions. Some rhymes are part of play, counting, games, teasing, while others are used solely for entertainment. Rhyme is also the linguistic element that is among the most characteristic of the multilingual forms of the collected examples of children's folklore.

Among the collected multilingual folklore units from Goriška brda, the most numerous are the counting-out rymes. They clearly show the linguistic heterogeneity of the area, as in individual units variants of both Slovenian and Italian variants are interwoven (e.g. in introductory formulations or in the concluding, counting part), or they consist of a linguistic mixture of words otherwise characteristic of the area. The texts of children's games, jears, teasers and lullabies are also short folklore forms in which multilingualism occurs.

The analysis of bilingual short folklore forms recorded in the Goriška brda showed that most of them belong to children's folklore. This is not surprising, since certain folklore genres and forms are often found in children's folklore as the last stages before disappearing from collective memory.

Thus, the children's folklore of a given area reveals the specifics of the society and, indirectly, its extinct or forgotten customs and folklore forms. Children's play and folklore also reflect the adult world, social structure and values. Thus, the presented examples of (children's) multilingual short folklore forms recorded in Goriška brda show the heterogeneity of the area's cultural practices and the area's interconnectedness, which crosses national borders and is clearly reflected in folklore.

Marjeta Pisk, Ph.D., Research Fellow, ZRC SAZU, Institute of Ethnomusicology, Novi trg 2, SI-1000 Ljubljana, marjeta.pisk@zrc-sazu.si

Katarina Šrimpf Vendramin, Ph.D., Research Fellow, ZRC SAZU, Institute of Slovenian Ethnology, Novi trg 2,SI-1000 Ljubljana, katarina.srimpf@ zrc-sazu.si 